\title{
LÍNGUA BRASILEIRA DE SINAIS: UMA ANÁLISE BIBLIOMÉTRICA DA REVISTA BRASILEIRA DE EDUCAÇÃO ESPECIAL E DA REVISTA DE EDUCAÇÃO ESPECIAL ENTRE 2015 E 2019
}

LENGUA DE SIGNOS BRASILEÑA: ANÁLISIS BIBLIOMÉTRICO DE LA REVISTA BRASILEÑA DE EDUCACIÓN ESPECIAL Y LA REVISTA DE EDUCACIÓN ESPECIAL ENTRE 2015 Y 2019

BRAZILIAN LANGUAGE OF SIGNS: A BIBLIOMETRIC ANALYSIS OF THE BRAZILIAN JOURNAL OF SPECIAL EDUCATION AND THE JOURNAL OF SPECIAL EDUCATION BETWEEN 2015 AND 2019

\section{Cristiane Silva Conceição \\ Especialista em Língua Brasileira de Sinais \\ Centro Universitário Leonardo da Vinci - Uniasselvi \\ c.s.cristiane@hotmail.com \\ ORCID - https://orcid.org/0000-0002-2361-4115}

\section{Dailza Araújo Lopes}

Mestra em Estudos Étnicos e Africanos

Universidade Federal da Bahia

dailzaaraujo@gmail.com

ORCID - https://orcid.org/0000-0002-0537-076X

\section{RESUMO}

0 presente estudo teve como objetivo investigar em que medida as publicações feitas na Revista Brasileira de Educação Especial (RBEE) e na Revista de Educação Especial (REE), entre 2015 e 2019, trazem a temática da Língua Brasileira de Sinais (Libras). A metodologia utilizada foi a pesquisa bibliométrica. Ao longo dos cinco anos analisados, foram publicados um total de 247 artigos e 1 resenha, na RBEE; e 341 artigos, na REE. Dessas publicações, foram encontrados com o descritor libras: nove publicações, na RBEE; e 45, na REE. Constatou-se também, através da nuvem de palavras, que os artigos com a temática Libras se relacionavam com mais frequência com os descritores "educação", "surdos" e "especial". Assim, concluímos que houve um crescente número de publicações com a temática de Libras em ambas as revistas, porém, devido à importância da discussão para o processo educacional da comunidade surda, é necessário que se amplie as possibilidades de divulgação da produção acadêmica na 
área da Libras, visto que esta já se consolida como uma área de produção científica dentro da Educação Especial.

Palavras-chave: Língua Brasileira de Sinais; Educação de Surdos; Educação.

\section{RESUMEN}

El presente estudio tuvo como objetivo investigar en qué medida las publicaciones realizadas en la Revista Brasileira de Educação Especial (RBEE) y Revista de Educação Especial (REE), entre 2015 y 2019, traen el tema de la Lengua de Signos Brasileña (Libras). La metodología utilizada fue la investigación bibliométrica. Durante los cinco años analizados, se publicaron en la RBEE un total de 247 artículos y 1 revisión; y 341 artículos en REE. De estas publicaciones se encontró el descriptor libras: nueve publicaciones, en RBEE; y 45, en REE. También se encontró, a través de la nube de palabras, que los artículos con el tema Libras estaban relacionados con mayor frecuencia con los descriptores "educación", "sordo" y "especial". Así, concluimos que hubo un número creciente de publicaciones sobre la temática de Libras en ambas revistas, sin embargo, debido a la importancia de la discusión para el proceso educativo de la comunidad sorda, es necesario ampliar las posibilidades de difusión de la producción académica en el área de Libras, dado que esta ya está consolidada como un área de producción científica dentro de la Educación Especial.

Palabra clave: Lengua de Signos Brasileña; Educación para sordos; Educación.

\section{ABSTRACT}

The present study aimed to investigate to what extent the publications made in the Brazilian Journal of Special Education (RBEE) and Journal of Special Education (REE), from 2015 to 2019, approached the theme Brazilian Sign Language "Libras". The methodology used was the bibliometrics method. Over the five years analyzed, a total of 247 articles and 1 review were published in RBEE; and 341 articles were circulated in ree. Among these publications, the descriptor "Libras" was found in: nine publications in RBEE; and 45 at ree. It was also found, through the word cloud, that the Libras themed articles were more frequently related to the descriptors "education", "deaf" and "special". So, we conclude that there was an increasing number of publications on the matter of Libras in both magazines, however, due to the importance of the discussion for the educational process of the deaf community, it is necessary to expand the possibilities of disseminating academic production in the area of Libras, since this is already consolidated as an area of scientific production within Special Education.

Keywords: Brazilian Sign Language; Deaf Education; Education. 


\section{Introdução}

A educação deve ser responsável por proporcionar aos sujeitos uma vida de possibilidades. Mas, para que isso aconteça, é necessário que todos os envolvidos nesse contexto participem verdadeiramente desse processo. A escola deve ser um espaço para todas as crianças, independentemente de suas condições físicas, intelectuais, sociais, religiosas, emocionais, raciais e linguísticas.

Em 1857, no Brasil, teve início, formalmente, a educação de surdos, com a fundação do Imperial Instituto de Surdos, pelo professor surdo Eduard Huent e o Imperador D. Pedro II, no Rio de Janeiro. A educação de surdos passou por várias concepções filosóficas em suas diferentes fases: oralismo, comunicação total e educação bilíngue.

Segundo Viera e Molina (2018, p. 15), "a partir do século 21, no Brasil, chega à discussão do bilinguismo como alternativa para educação dos surdos, reconhecendo a Língua Brasileira de Sinais como a primeira língua dos surdos". 0 reconhecimento da Libras como língua oficial não pôs fim, nem deveria, às discussões a respeito da educação de surdos.

A partir do que já foi exposto, surge o problema que norteou este estudo: em que medida as publicações feitas na Revista Brasileira de Educação Especial (RBEE) e na Revista de Educação Especial (REE), entre 2015 e 2019, trazem como temática a Libras?

Nesse contexto, surge o objetivo geral do presente estudo: investigar em que medida as publicações feitas na Revista Brasileira de Educação Especial e na Revista de Educação Especial, entre 2015 e 2019, trazem a temática de Libras. E como objetivos específicos: apresentar um breve histórico da educação de surdos; investigar a incidência de publicação de artigos sobre Libras na Revista Brasileira de Educação Especial e na Revista de Educação Especial.

Visando perceber quais são as abordagens das pesquisas com relação à Língua Brasileira de Sinais (Libras), na Revista Brasileira de Educação Especial (RBEE) e na 
Revista de Educação Especial (REE), entre 2015 e 2019, que esse estudo foi realizado, a partir da metodologia da pesquisa bibliográfica, utilizando a bibliometria, que consiste em análise de conteúdo, pauta-se pelo princípio de analisar a atividade científica ou técnica pelos estudos quantitativos das publicações.

\section{A trajetória da educação de surdos}

$\mathrm{Na}$ antiguidade, os surdos não eram vistos como sujeitos pertencentes à sociedade. A conquista do seu lugar nesse espaço aconteceu com o desenvolvimento do "alfabeto manual" e foi consolidado com as pesquisas que proporcionaram uma melhor compreensão da surdez.

Segundo Campelo (2009, p.13), a trajetória da educação de surdos tem início com a criação do alfabeto manual pelo San Buanaventura (Frei Juan de Fidanz, 12211274), na França. O sistema teria sido criado pelo Frei para ele se comunicar com outros companheiros pelo voto de silêncio, sendo aproveitado para ensinar os surdos da época e assim integrá-los ao meio social. Na Idade Moderna, os surdos aprenderam a ler e a escrever com os monges. Alguns livros e métodos foram publicados com o alfabeto manual, ensinando a usar os sinais e escrita, outros utilizavam a via da oralização. No Renascimento, as ações negativas em relação aos surdos foram reduzidas.

No século XVIII, a capital francesa e as cidades vizinhas já apresentavam diversas comunidades surdas. $\mathrm{O}$ abade Charles Michel de L’Epée aprendeu a língua de sinais através de duas irmãs gêmeas e da população mais carente. Posteriormente, começou a ensinar na sua própria casa a língua de sinais e a gramática francesa. Fundou a primeira escola pública, denominada Instituto para Jovens Surdos e Mudos de Paris, que treinou inúmeros professores (CAMPELLO, 2009).

\section{As Práticas pedagógicas na educação dos surdos no Brasil}

Em 1ํ de janeiro de 1856, no Rio de Janeiro, teve início a educação de surdos no Brasil, com o funcionamento do Instituto Nacional para Surdos-Mudos. Atualmente, denominando Instituto Nacional de Educação de Surdos, proposto pelo francês, conde, 
surdo e professor Eduard Huet. Ele apresentou a proposta ao Imperador Dom Pedro II, que confiou ao Marques de Abrantes a criação da primeira escola de surdos no Brasil. Na escola, as crianças e jovens surdos tinham contato com várias disciplinas junto com a língua de sinais francesa e a introdução de novos sinais no Brasil. Nas décadas iniciais, do século XX, o instituto começou a oferecer o ensino profissionalizante. (ALVES et. al., 2014)

A educação de surdos no Brasil passou por diferentes concepções pedagógicas nas suas três fases: oralismo, comunicação total e bilinguismo. 0 oralismo tinha como objetivo usar práticas para tornar os surdos pessoas ouvintes. Várias metodologias eram realizadas por profissionais de diferentes áreas, visando a recuperação da audição deles. Nessa fase, considerava-se que o resultado da prática pedagógica dependia da vontade do indivíduo e de sua família. Para Almeida (2015):

A prática oralista complica o progresso dos surdos quanto ao uso e desenvolvimento de sua língua natural, no Brasil, a Língua Brasileira de Sinais - Libras, surgindo, assim, uma interlíngua, justamente porque as pessoas envolvidas no processo de educação dos surdos não são surdas e não são falantes naturais da Língua de Sinais. Mesmo que sejam muito fluentes na língua, elas precisam "entrar na língua". (ALMEIDA, 2015, p. 31).

Segundo Lopes e Freitas (2016), o método do oralismo começou a ter sua eficácia questionada devido ao fracasso com diversos estudantes que não apresentaram condições para realizar a produção de sons. Com isso, a comunicação total foi conquistando espaço, sendo considerada por alguns autores como parte do oralismo. Nesse método, a comunicação era realizada com a emissão de sons, leitura dos lábios, tendo como suporte mímicas, gestos e todos recursos que promovessem a comunicação. 0 sucesso escolar pelos surdos também não foi alcançado com a comunicação total, acredita-se que devido à semelhança com o oralismo.

No início do século XXI, o bilinguismo foi a alternativa proposta para a educação dos surdos. Essa concepção reconhece a Libras como a primeira língua (L1) dos surdos e a Língua Portuguesa como a segunda (L2). 
No Brasil (1988), a Constituição Federal Brasileira, no Capítulo III — Da Educação, da Cultura e do Desporto, artigo 208, prescreve que o dever do Estado com a educação será efetivado mediante a garantia de “[...] atendimento educacional especializado aos portadores de deficiência [sic], preferencialmente na rede regular de ensino".

Um desses atendimentos necessários para proporcionar a comunicação com as pessoas surdas é o ensino da Língua Brasileira de Sinais (Libras). Nessa concepção, são usadas como ferramentas a Língua de Sinais, o espaço visual e a Língua Portuguesa oral-auditiva, sendo que a Libras é considerada como a primeira língua dos surdos.

A Lei no 10.436/02, que reconhece a Língua Brasileira de Sinais (Libras) como meio legal de comunicação e expressão, determina que sejam garantidas formas institucionalizadas de apoiar seu uso e difusão, bem como a inclusão da disciplina de Libras como parte integrante do currículo nos cursos de formação de professores e de fonoaudiologia.

O governo federal e a comunidade surda têm propostas diferentes para a educação dos surdos. Lodi (2013) afirma que a Política Nacional de Educação na Perspectiva da Educação Inclusiva defende educação especial, a qual considera inclusão de surdos no sistema regular de ensino. Já a comunidade surda propõe que a educação constitui um campo específico do conhecimento, com base no Decreto $\mathrm{n}^{\circ} 5.626 / 05$ promulgado após a Lei $\mathrm{n}^{\circ}$ 10.436/02.

\section{Metodologia}

Para realização desta pesquisa, foi utilizada a abordagem bibliométrica e análise de conteúdo. Na concepção de Silva e Hayashi (2018, p. 67), "bibliometria pauta-se pelo princípio de analisar a atividade científica ou técnica pelos estudos quantitativos das publicações, ou seja, por meio dessa abordagem". Ainda sobre o estudo bibliométrico, Scardo (2012, p. 18 apud SILVA; HAYASHI, 2018, p. 67) completou: 
[...] os estudos bibliométricos são úteis para mapear um campo científico, avaliar a pesquisa acadêmica, "[...] bem como para orientar rumos e estratégias de financiamento de pesquisas e apontar o alcance analítico para o estudo de um campo científico". (SCARDO apud SILVA E HAYASHI, 2018, p. 67).

A fonte de investigação para este artigo foi a Revista Brasileira de Educação Especial e a Revista de Educação Especial. Foram selecionadas publicações das revistas entre os anos de 2015 e 2019, por meio de buscas na biblioteca eletrônica da SciELO (Scientific Electronic Library Online) e no site das revistas, nos volumes anteriores ao ano de 2019. 0 descritor utilizado foi a palavra "libras".

Os dados coletados foram inseridos em uma tabela Excel para registro das informações, visando analisar como a temática Libras tem sido abordada nas revistas estudadas.

O portal de periódicos da Coordenação de Aperfeiçoamento de Pessoal de Nível Superior (Capes) é um acervo virtual que reúne e divulga produções científicas. Nessa plataforma, ao procurar periódicos com o tema da "Educação Especial", foram encontrados os seguintes resultados: Revista Brasileira de Educação Especial e Revista de Educação Especial.

A Revista Brasileira de Educação Especial (RBEE) foi criada pela Associação Brasileira de Pesquisadores durante o III Seminário de Educação, em 1993, no Rio de Janeiro. A Revista de Educação Especial (REE) foi criada em 1987, pela Universidade de Federal de Santa Maria, com o objetivo de publicar artigos inéditos resultantes das pesquisas e das práticas no campo da área da educação especial. Ambos os periódicos têm como objetivo contribuir com a disseminação de pesquisas na área de Educação Especial afins.

A escolha da Revista Brasileira de Educação Especial (RBEE) e da Revista de Educação Especial (REE) como objeto de investigação se deu pelos seguintes motivos: 1) sãos os periódicos mais antigos da área; 2) as revistas ocupam o segundo estrato de qualis-periódicos da Capes, o A2, o que evidência sua importância na divulgação de temas relevantes para a área da Educação Especial; 3) regularidades das revistas. Em relação ao recorte temporal adotado, foi definido como parâmetro as pesquisas 
realizadas entre 2015 e 2019, a fim de compreender o estado da arte das pesquisas no campo da Libras e quais são as abordagens mais frequentes.

A escolha do descritor "Língua Brasileira de Sinais (LIBRAS)" para realização do estudo deve-se à importância da utilização dessa língua para a comunicação com as pessoas surdas e, consequentemente, para viabilizar o caminhar desses sujeitos na escola e em diversos outros espaços.

O levantamento dos dados foi realizado em duas etapas: primeiro, utilizando a ferramenta de busca online no site da revista/periódico, inserindo ao campo de pesquisa a palavra-chave "Libras". Posteriormente, foram selecionadas publicações das revistas RBEE e REE que apresentaram o descritor Libras, nos volumes entre o ano 2015 e 2019.

Visando responder à pergunta de pesquisa elencada inicialmente, foram analisados os seguintes parâmetros: total de publicações, tipologia dos artigos e análise das palavras-chaves através da nuvem de palavras. Utilizou-se a técnica "nuvem de palavras" através da página wordclouds para a análise das palavras-chaves presentes nos artigos selecionados. A construção da nuvem tem como objetivo analisar conteúdos através da frequência das palavras num determinado contexto. As palavras mais utilizadas apresentam uma fonte gráfica maior e aparecem na parte mais central do texto; as menos utilizadas, em tamanhos menores e nas partes mais afastadas do centro. Assim, é possível observar visualmente as palavras-chaves mais relevantes.

\section{Resultados e discussão}

Ao longo dos cinco anos analisados, foram publicados, na RBEE, um total de 247 artigos e uma resenha; e 341 artigos, na REE. Dessas publicações, foram encontradas nove publicações na RBEE; e 45, na REE.

As nove publicações com o descritor Libras, na RBEE, foram distribuídas da seguinte forma: relato de pesquisa $(n=8)$ e revisão de literatura $(n=1)$. Na REE, as quarentas e cinco publicações foram assim distribuídas: artigos $(n=32)$, relato de 
pesquisa $(\mathrm{n}=2)$, direitos linguísticos dos surdos: concepções e práticas inclusivas $(n=11)$.

Dessa forma, considera-se que a maioria das publicações são em forma de artigos científicos. Entretanto, é necessário ressaltar que até o ano de 2018 todas as publicações da revista eram denominadas artigos. A divisão dos periódicos em sessões (revisão de literatura ou artigos empíricos) só aconteceu na REE, a partir de 2019.

Os demais resultados são apresentados a seguir, na Tabela 1, e expõe a quantificação dos artigos publicados entre 2015 e 2019, bem como a totalidade dos artigos que trazem como temática a Língua Brasileira de Sinais no contexto de publicação da Revista Brasileira de Educação Especial:

Tabela 1: quantidade de publicação na Revista Brasileira de Educação Especial 2015-2019

\section{Revista Brasileira de Educação Especial}

\begin{tabular}{ccc}
\hline Ano & Publicações totais & $\begin{array}{c}\text { Publicações com a } \\
\text { temática Libras }\end{array}$ \\
\hline
\end{tabular}

2015 (quatro edições)

40 artigos

1 resenha

\begin{tabular}{lll}
\hline 2016 (quatro edições) & 40 artigos & 0 \\
\hline 2017 (quatro edições) & 40 artigos & 3
\end{tabular}

\begin{tabular}{ccc}
\hline $\begin{array}{c}\text { 2018 (cinco edições + } \\
\text { edição especial) }\end{array}$ & 45 artigos & 2 \\
\hline 2019 (quatro edições) & & 2 \\
\hline Total & 45 artigos & $\mathbf{9}$ \\
\hline
\end{tabular}

Fonte: produção das autoras, 2020. 
Conforme observa-se na tabela acima, foram publicadas quatro edições por ano, no período de 2015-2019. Entretanto, em 2018, a revista publicou mais uma edição, classificada como especial, para comemorar seus 25 anos de história.

Ao longo das 21 edições, foram publicados 207 artigos e 1 resenha. Desses artigos, nove tinham o descritor Libras. 0 ano com maior número de publicações com o esse descritor foi 2017, com 3 artigos. Já o ano com menor incidência foi 2016, sem nenhum artigo publicado.

Verificou-se, portanto, que na Revista Brasileira de Educação Especial, ao longo dos últimos cinco anos, publicou 207 artigos e uma resenha. Desses, na busca das publicações com o descritor Libras, apenas nove artigos foram encontrados. Considerando essa quantidade nos últimos cinco anos, observa-se que ainda há um baixo índice de publicações sobre a referida temática nessa revista.

Assim, torna-se necessário pensar ações diretamente ligadas ao fortalecimento e incentivo dessas pesquisas na área da Libras dentro da referida revista. Hayashi (2011) realizou estudos sobre o conhecimento científico produzido na área de educação especial e conclui que:

Os estudos de análise da produção científica no campo da educação especial têm apontado diferentes perspectivas teóricas, conceituais e metodológicas, com relação aos objetos de estudo e abordagens, indicando aos pesquisadores da área que a diversidade de perspectivas propicia um diálogo entre as múltiplas formas de aprofundamento teórico-conceitual da área. (HAYASHI, 2011, p. 153).

Considerando que a Educação Especial é um campo de estudo abrangente, as publicações da Revista Brasileira de Educação Especial podem ser enriquecidas ao ter pesquisas de várias áreas do conhecimento, tendo a Libras como ponto de ligação, visto que a língua é interdisciplinar e atravessa cotidianamente vários espaços.

A fim de melhor apresentar os artigos que foram publicados com a temática de Libras, foi elaborada uma nuvem de palavras em que é possível analisar as palavras que possuem mais incidência nos artigos publicados, conforme segue na imagem abaixo. 
Figura 1: nuvem de palavras dos descritores da Revista Brasileira de Educação Especial

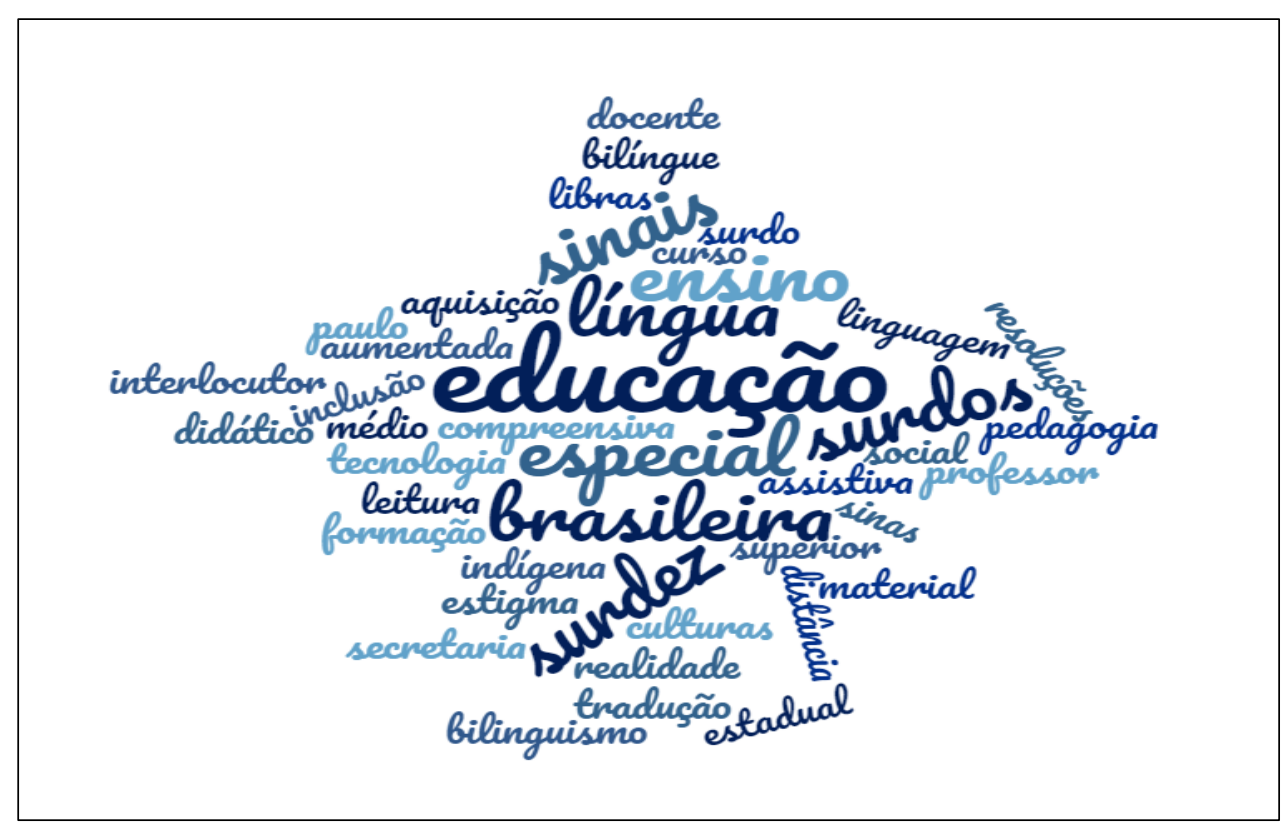

Fonte: produção das autoras, 2020.

Das quarenta e cinco publicações presentes na Revista Brasileira de Educação Especial, refletind o o caminhar das pesquisas localizadas a partir do descritor Libras, publicadas entre 2015 e 2019, verificou-se que os descritores que mais se destacam, em ordem decrescente, são os seguintes: educação $(n=14)$; especial $(n=8)$; surdez $(n=4)$; ensino $(n=4)$; surdos $(n=2)$; aquisição e demais descritores $(n=1)$. Nesse contexto, as publicações da RBEE estão ligadas à educação e ao ensino, o que denota a importância da Libras nesse contexto de ensino e aprendizagem, principalmente de pessoas surdas, mas que se configura como sendo de fundamental importância que pessoas ouvintes estejam inseridas dentro da cultura surda através da Libras, pois, conforme aponta reportagem da Agência Senado, "Baixo alcance da língua de sinais leva surdos ao isolamento" ${ }^{1}$, conforme aponta Weinstin (2019):

Raras escolas estão adaptadas para receber alunos surdos. A mera presença de um intérprete da língua de sinais ao lado do professor não é suficiente. Por um lado, muitas crianças surdas chegam ao colégio sem saber língua nenhuma e vão ter que aprender a Libras do zero. Por outro, as que já sabem a língua de sinais não encontram professores preparados para ensinar-lhes o português escrito. Nessa situação, como a Libras é a primeira língua do estudante, o português

${ }^{1}$ Disponível em: <https://www12.senado.leg.br/noticias/especiais/especial-cidadania/baixo-alcanceda-lingua-de-sinais-leva-surdos-ao-isolamento>. Acesso em: 26 jul. 2020. 
precisa ser apresentado como segundo idioma, com uma metodologia completamente diferente, tal como uma língua estrangeira. 0 professor precisa ser bilíngue e ter uma formação específica. (WESTIN, 2019, s/p [online]).

Portanto, percebe-se que, apesar do crescimento da Libras como L1, a exclusão de pessoas surdas pode continuar sendo uma prática constante na sociedade, pois a barreira linguística imposta tem características da cultura ouvinte e pode ser historicamente desconstruída tendo o ensino da L1 e L2 para pessoas surdas, e L2 e L1 para pessoas ouvintes.

Na tabela 2, estão os dados referentes às informações construídas, considerando a Revista de Educação Especial, entre o período estudado nesta pesquisa. É importante analisar de forma comparativa o crescimento de publicações na área da Libras.

Tabela 2: quantidade de publicações na Revista de Educação Especial no período de 2015-2019

\begin{tabular}{|c|c|c|}
\hline \multicolumn{2}{|c|}{ Revista de Educação Especial } \\
\hline Ano & Total de publicações & Publicações com a temática Libras \\
\hline 2015 (três edições) & 54 & 5 \\
\hline 2016 (três edições) & 51 & 2 \\
\hline 2017 (três edições) & 52 & 5 \\
\hline 2018 (quatro edições) & 64 & 30 \\
\hline 2019 (publicação contínua) & 120 & $\mathbf{4 5}$ \\
\hline Total & $\mathbf{3 4 1}$ & \\
\hline
\end{tabular}

Fonte: produção das autoras, 2020.

Foram publicadas três edições por ano, no período de 2015 até 2017. Entretanto, em 2018, foram quatro edições; em 2019, uma. Ao longo das 14 edições, foram publicados 341 artigos. Desses artigos, quarenta e cinco com resultado da busca do descritor Libras. 0 ano com maior número de publicações foi 2019; e o menor, em 2015, com três. Em relação ao aumento de artigos publicados, devemos ressaltar que no ano de 2019 a edição apresentou uma seção denominada "Dossiê - Direitos 
Linguísticos dos Surdos: concepções práticas inclusivas.”. Esse fato contribuiu para o aumento das publicações.

De acordo com as informações levantadas e as análises realizadas, aponta-se que há um evidente crescimento do interesse por pesquisas científicas no ano de 2019. A nuvem de palavras a seguir foi construída a partir dos descritores dos artigos que têm a temática de Libras, na Revista de Educação Espacial, a fim de evidenciar a incidência de palavras e sua relação com a discussão iniciada no presente trabalho.

Figura 2: nuvem de palavras dos descritores da Revista de Educação Especial

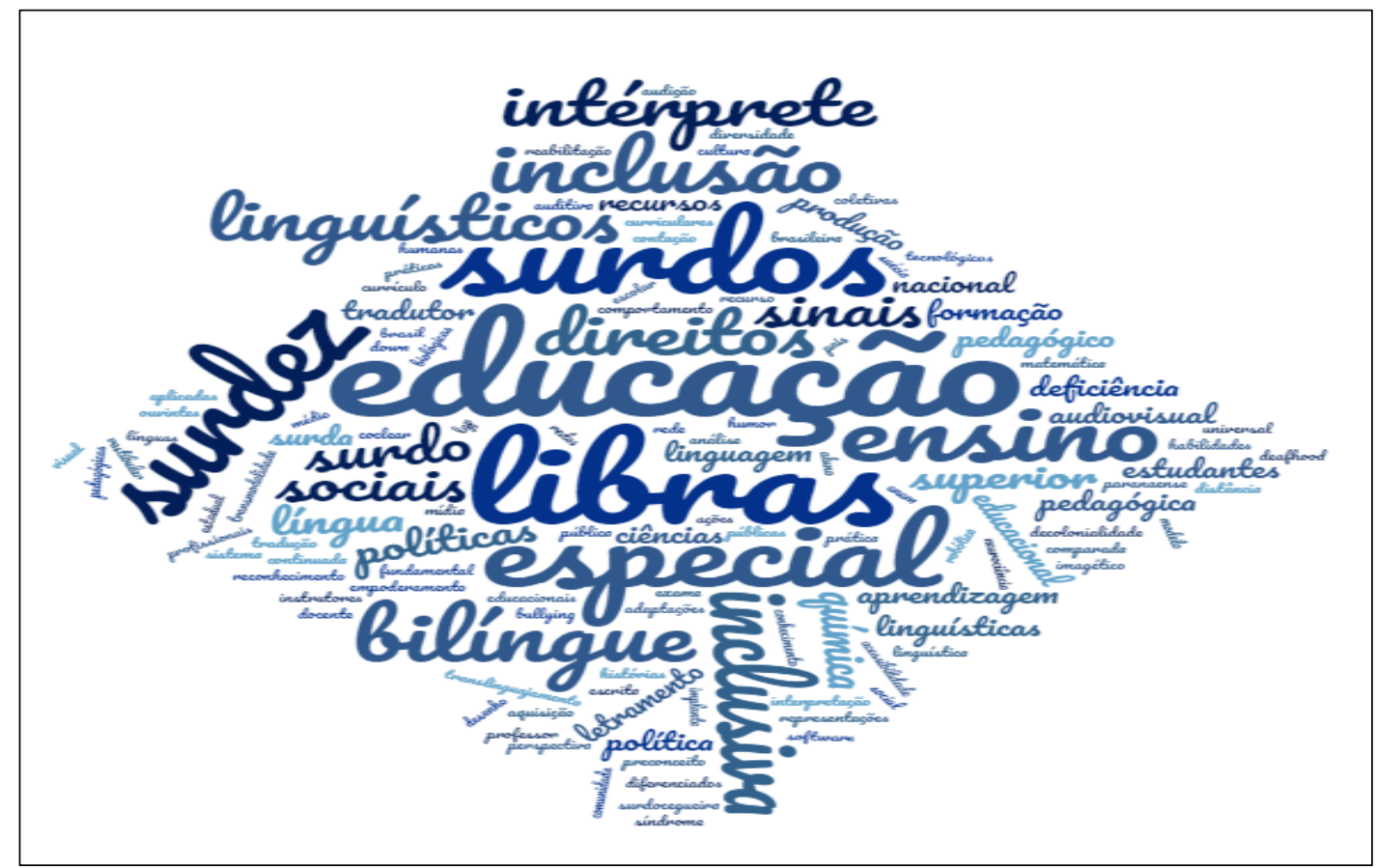

Fonte: produção das autoras, 2020.

Assim, das 45 publicações da Revista Brasileira de Educação Especial, refletindo o caminhar das pesquisas sobre o descritor Libras, publicadas entre 2015 e 2019, verificou-se que os descritores que mais se destacaram, em ordem decrescente, são os seguintes: educação $(n=27)$; surdos $(n=11)$; especial $(n=9)$; surdez $(n=8)$; ensino $(n=7)$; bilíngue $(n=6)$; inclusiva e inclusão $(n=6)$; direitos, intérprete, linguísticos e surdo $(\mathrm{n}=5)$; políticas, sinais, sociais, superior, língua $(\mathrm{n}=4)$ química $(\mathrm{n}=3)$; aprendizagem, audiovisual, ciências, deficiência, educacional, estudantes, formação, letramento, 
linguagem, linguísticas, nacional, pedagógica, pedagógico, política, produção, recursos, surda e tradutor $(n=2)$; acessibilidade e demais descritores com ocorrência $(n=1)$.

Percebe-se que os descritores que mais estão em incidência direcionam para o bilinguismo e a inclusão. Nessa relação intrínseca, Santos e Goes (2016) apontam:

A inclusão é um instrumento necessário para garantir equidade entre pessoas com ou sem deficiência e produzir uma sociedade mais justa e igualitária. É também neste quadro que a LIBRAS se tornou um meio de acessibilidade para surdos, garantindo acesso igualitário à comunicação, informação e educação. (SANTOS; GOES, 2016, p. 157).

Outro descritor que chama a atenção, no contexto das propostas de inclusão, é “intérprete". A Lei 12.319/2010 vem para regulamentar a profissão de Tradutor e Intérprete da Língua Brasileira de Sinais, abrindo precedentes para o início de processos de inclusão nos diversos espaços e que, com o avanço da legislação de Educação Espacial como foco para a Libras, tem possibilitado que algumas mudanças sejam realizadas, como, por exemplo, a disponibilização de intérprete em diversos espaços públicos (saúde, educação, assistência social), a fim de atender às pessoas surdas que necessitam daquele serviço.

Considerando o contexto de escrita da presente pesquisa, que está sendo realizada no período em que a pandemia desencadeada pela COVID-19, tem chamado a atenção a presença das(os) intérpretes da Libras nas lives ${ }^{2}$ e outros eventos realizados de forma online (webinários ${ }^{3}$ ). Esse fato vem sendo motivo de avanço para que novas práticas de quebra das barreiras linguísticas possam ser construídas. Além de possibilitar reflexões a respeito da inclusão, aponta também para um aumento na procura por cursos de Libras 4 .

\footnotetext{
2Transmissão ao vivo usando as tecnologias da informação e da comunicação.

${ }^{3}$ Nome dado aos seminários antes realizados de forma presencial, e que, a agora, estão sendo realizados através do uso da internet. Por isso, a adaptação do termo para "webinário".

${ }^{4}$ Disponível em: <https://oglobo.globo.com/rio/bairros/libras-apos-sucesso-nas-lives-aumentaprocura-de-cursos-da-lingua-de-sinais-24499751>. Acesso em: 26 de jul. 2020.
} 
Outro fato interessante é que tem se usado para falar de Libras a "educação dos alunos surdos". Ressalta-se a importância do uso do descritor "Libras" em pesquisas na área como forma de localizar a produção científica.

Do ponto de vista acadêmico, as pesquisas realizadas dão base para a produção de políticas públicas e, nesse contexto, a Libras pode possibilitar mais que a educação de alunos e alunas surdas, é a configuração de uma sociedade mais inclusiva nos diversos setores, como, por exemplo, o mercado de trabalho, o acesso a bens e serviços, a educação, a cultura, o lazer e novas possibilidades de existência para a comunidade surda.

"É necessário romper com os padrões convencionais de ensino e de aprendizagem, e criar condições para efetivar um processo em que todos contribuam para concretização, de fato, do direito de aprender." (PEREIRA; GUIMARÃES, 2019, p. 572). Portanto, é preciso refletir sobre os caminhos da Educação Especial para garantir a inclusão, principalmente quando se trata de um campo específico como é o caso da Língua Brasileira de Sinais.

\section{Considerações finais}

Após a análise bibliométrica da Revista Brasileira de Educação Especial (RBEE) e da Revista de Educação Especial (REE), no período de 2015 a 2019, foi possível constatar as publicações com o descritor Libras: cinquenta e quatro, de um total de quinhentas e oitenta e oito publicações. Resultado que se configura como bastante baixo, considerando o alcance das referidas revistas e classificação junto à CAPES. Torna-se importante elencar que a Libras já é consolidada como uma área de produção científica dentro da Educação Especial. Como as revistas são especializadas no estudo da temática referida, os indicadores demostraram que ela é pouco discutida, considerando todo o período analisado.

Dessa forma, constatou-se que a maioria das publicações da RBEE foram em forma de artigos científicos, ligados à educação e ao ensino, o que denota a importância 
da Libras no espaço formativo escolar, de ensino e aprendizagem, principalmente de pessoas surdas, mas que se configura como sendo de fundamental importância para pessoas ouvintes, devido à necessidade de quebra das barreiras linguísticas.

Já na REE, as publicações direcionam para a temática do bilinguismo e a inclusão, denotando a importância da Libras como L1 para os surdos e L2 para os ouvintes, a fim de ampliar a comunicação e a proposta de inclusão. E destaca para o papel do intérprete em Libras, sobretudo, nesse contexto de pandemia, mas também em diversos outros momentos, como forma de possibilitar o acesso de pessoas surdas a bens e serviços.

Portanto, propõe-se, como forma de ampliar as publicações na área de Libras, que a Revista Brasileira de Educação Especial possa, se possível, disponibilizar um volume da revista para receber artigos especificamente do campo da Libras, como forma de valorizar, fortalecer e disseminar o conhecimento já produzido cientificamente sobre ou relacionada à Língua Brasileira de Sinais, semelhante ao Dossiê - Direitos Linguísticos dos Surdos: concepções práticas Inclusivas, publicado pela Revista de Educação Especial no ano de 2019.

\section{Referências}

ACERVO do Ines. Ribeiro, Adalberto. 0 Instituto Nacional de Surdos Mudos. Disponível em:<http://repositorio.ines.gov.br/ilustra/bitstream/123456789/480/1 Revista_do_servico_publico.pdf>. Acesso: em 05 de jan.2019

ALVES, F. C. et.al. Educação de surdos em nível superior: desafios vivenciados nos espaços acadêmicos. In: ALMEIDA, WG., (Org.). Educação de surdos: formação, estratégias e prática docente [online]. Ilhéus, BA: Editus, 2015. p. 27-47.

ALMEIDA, WG., (Org.). Educação de surdos: formação, estratégias e prática docente [online]. Ilhéus, BA: Editus, 2015.

BRASIL. Decreto n. 5.626, de 22 de dezembro de 2005. Regulamenta a Lei no 10.436, de 24 de abril de 2002, que dispõe sobre a Língua Brasileira de Sinais - Libras, e o art. 18 da Lei no 10.098, de 19 de dezembro de 2000. Disponível em: http://www.planalto.gov.br/ccivil 03/ ato2004-2006/2005/decreto/d5626.htm Acesso em: 29 de dez. 2019. 
BRASIL, Política Nacional de Educação Especial na Perspectiva da Educação Inclusiva. Brasília: MEC/SEESP, 2008. Disponível em:

http://portal.mec.gov.br/seesp/arquivos/pdf/politica.pdf Acesso em: 12 de jan. 2020.

CAMPELLO, A. R.S. Deficiência Auditiva e Libras. Centro Universitário Leonardo da Vinci-Indial: Grupo Uniasselvi, 2009.

FRAZÃO, N. F.; LODI, A. C. B. Associação de Surdos de São Paulo e a defesa pelos direitos linguísticos dos surdos. Revista Educação Especial, v. 32, 2019, Santa Maria. Disponível em: https://periodicos.ufsm.br/educacaoespecial Acesso em: 4 de jan.2020.

HAYASHI, M. C. P. I. Múltiplos olhares sobre a produção do conhecimento em Educação Especial. Diálogo Educacional, 11(32), 145-165, 2011. Disponível em: https://periodicos.pucpr.br/index.php/dialogoeducacional/article/view/4108 Acesso em: 26 de jul. 2020.

INSTITUTO Nacional de Educação de Surdos. Disponível em: http://ines.gov.br/conheca-o-ines Acesso em: 05 de jan.2020.

LODI. A. C. A educação bilíngue para surdos e inclusão segundo a Política Nacional de Educação Especial e o Decreto n0 5.626/05. Revista de Educação e Pesquisa, v.39, n.1, p. 49-63,2013. São Paulo. Disponível em:

http://www.scielo.br/pdf/ep/v39n1/v39n1a04.pdf Acesso em: 18 de set. 2019.

LOPES, S. C.; FREITAS, G. M. A construção do projeto bilíngue para surdos no Instituto Nacional de Educação de Surdos na década de 1990. Revista Brasileira de Estudos Pedagógicos. Brasília, DF, v. 97, n. 246, p. 372 - 386, ago. 2016. Disponível em: https://www.scielo.br/scielo.php?script=sci abstract\&pid=S217666812016000200372\&lng=en\&nrm=iso\&tlng=pt. Acesso em: 23 de abr. 2020.

MANTOAN. M. T. E. Inclusão escolar: o que é? por quê? como fazer? São Paulo: Moderna, 2003.

PEREIRA, C. A. R.; GUIMARÃES, Selva. A Educação Especial na Formação de Professores: um Estudo sobre Cursos de Licenciatura em Pedagogia. Revista Brasileira de Educação Especial, [s.l.], v. 25, n. 4, p.571-586, dez. 2019. FapUNIFESP (Scielo). Disponível em: http://dx.doi.org/10.1590/s1413-65382519000400003 Acesso em: 12 de jan. 2020.

SANTOS; A. P. S.; GOES; R. S. Língua brasileira de sinais - libras. UNIASSELVI, 2016.

SILVA, J. H.; HAYASHI, M. C. P. I. Estudo bibliométrico da produção científica sobre a associação de pais e amigos dos excepcionais. Revista Educação Especial. v. 31; n. 60 p. $65-80$ jan./mar. 2018. Disponível em: https://periodicos.ufsm.br/educacaoespecial Acessado em: 11 de jan. 2020.

VIERA, C. D.; MOLINA, K. S. M. Prática pedagógica na educação de surdos: o entrelaçamento das abordagens no contexto escolar. Educação e Pesquisa, v. 44, 2018, São Paulo. Disponível em: 
http://www.scielo.br/scielo.php?script=sci arttext\&pid=S151797022018000100503 Acesso em: 18 de jan. 2019. 